\title{
Application Research on Modularity Design Pattern of Children's Bicycle
}

\author{
Fang Li \\ Department of Industrial Design \\ Suzhou Art and Design Technology Institute \\ Suzhou, Jiangsu, China 215000
}

\begin{abstract}
As a new kind of production thought, modularity production is affecting development of every walk of life. Current production method of children's bicycle can not satisfy people's need. Without using the method of modularity production, manufacturers spend too long time designing and producing products according to client requirement. They also have to redesign and reproduce based on requirements of different clients. For this purpose, after analyzing features of children's bicycle, this paper combines modularity production theory, uses function decomposition approach to optimize design and production, establishes model analysis and discusses feasibility of applying modularity production. The paper takes children's bicycle as the object of modularity design, and establishes different modules according to component system of function module after using function decomposition approach to analyze each component. It displays the upgrade path of children's bicycle after applying modularity design through building models.
\end{abstract}

Keywords-children's bicycle; modularity; function decomposition approach

\section{INTRODUCTION}

"Modularity design" is a new design concept and method proposed by European and American countries in the last century. Since market has higher and higher requirements for variety, quantity, performance and quality of mechanical and electrical products, traditional design methods can hardly satisfy them. Therefore, the so called modern design method appears and it solves the contradiction from a different angle. modularity design is a kind of modern design method which emphasizes on contradictions between variety and specification of product, design and manufacturing cycle time and cost. Children are the future and hope of social development and progress[1]. Development of bicycle industry begins after World War II. Up to now, main bicycle manufacture area has come into being, and bicycle industry becomes quite successful. Resilience and speed have become the key elements for enterprise's survival in intensely competitive market supply chain environment. Challenges include little customizing time and contraction of product's life cycle ( Zhou Yuxian, 2003) and so on[2-3]. Therefore, how to use current information integration technology to conduct trans-department and trans-regional synchronization operation process and synchronous operation of supply chain systems in upstream and downstream post a great opportunity to explore market nowadays. Suh proposes an independent axiom in 1990: "A good design has to fully consider independence"[4]. Jia Yanlin emphasizes on functional analysis in design process and requires module division based on it[5]. Ulirch and Tung puts forward that product's physical components and their function allocation are corresponding to each other in modularity design and interface of different modules should be weakened as much as possible[6]. However, nowadays, most children's bicycle dealers still take traditional design as main development mode. Therefore, it is extremely necessary to improve current situation of bicycle design industry and improve the overall development mode. This paper plans to start with design, apply currently existed design information technology and introduce modularity design to make children's bicycle design faster and more flexible and to increase benefit of developing children's bicycle.

\section{DEFINITION OF MODULARITY DESIGN}

Modularity design is a kind of design strategy, which means using component module in common to create product variability. Its purpose is to use independent, standard and replaceable module unit to satisfy variability of product function. Based on functional analysis on products with different functions or with same functions and different properties and different specifications in a certain range, module design divides and designs a series of functional modules, and creates customized products for clients through selection and combination of module to meet different needs of market. Development concept of module mainly comes from Germany and it applies building block composition concept. The so called modularity refers to integrating some standard units into modules with different functions or models through combination and collocation of plural function module, forming new products rapidly and effectively to satisfy client's need, and matching and changing functional modules based on standardized interface to achieve diversified effect[7]. In his book The Age of Modularity, O.Grady deeply analyzes definition, content and application instance of modularity and defines modularity as: Modularity is to composite each component in component groups to form products. The interior of each module might be very complex, but we must have a clear outside boundary and a definite interface. The effect of an interface lies in ensuring that modules can connect with each other, combine in different ways and achieve the goal of product diversification in short time[8-10]. 


\section{MOdUlarity Design Pattern OF CHILDREN'S BICYCLE}

Application of modularity approach in design and production of children's bicycle still stays in proposal phase and it is detached from systematic guidance in terms of practicability. Therefore, it is extremely necessary to deep explore a kind of scientific and effective modularity design approach for children's bicycle.

\section{A. Proposal of Function Decomposition}

It is a necessary condition and process for realization of modularity design to refine children's bicycle to achieve standardization, component universalization and model serialization. Product component production steps of children's bicycle after applying modularity are as follows "Fig. 1":

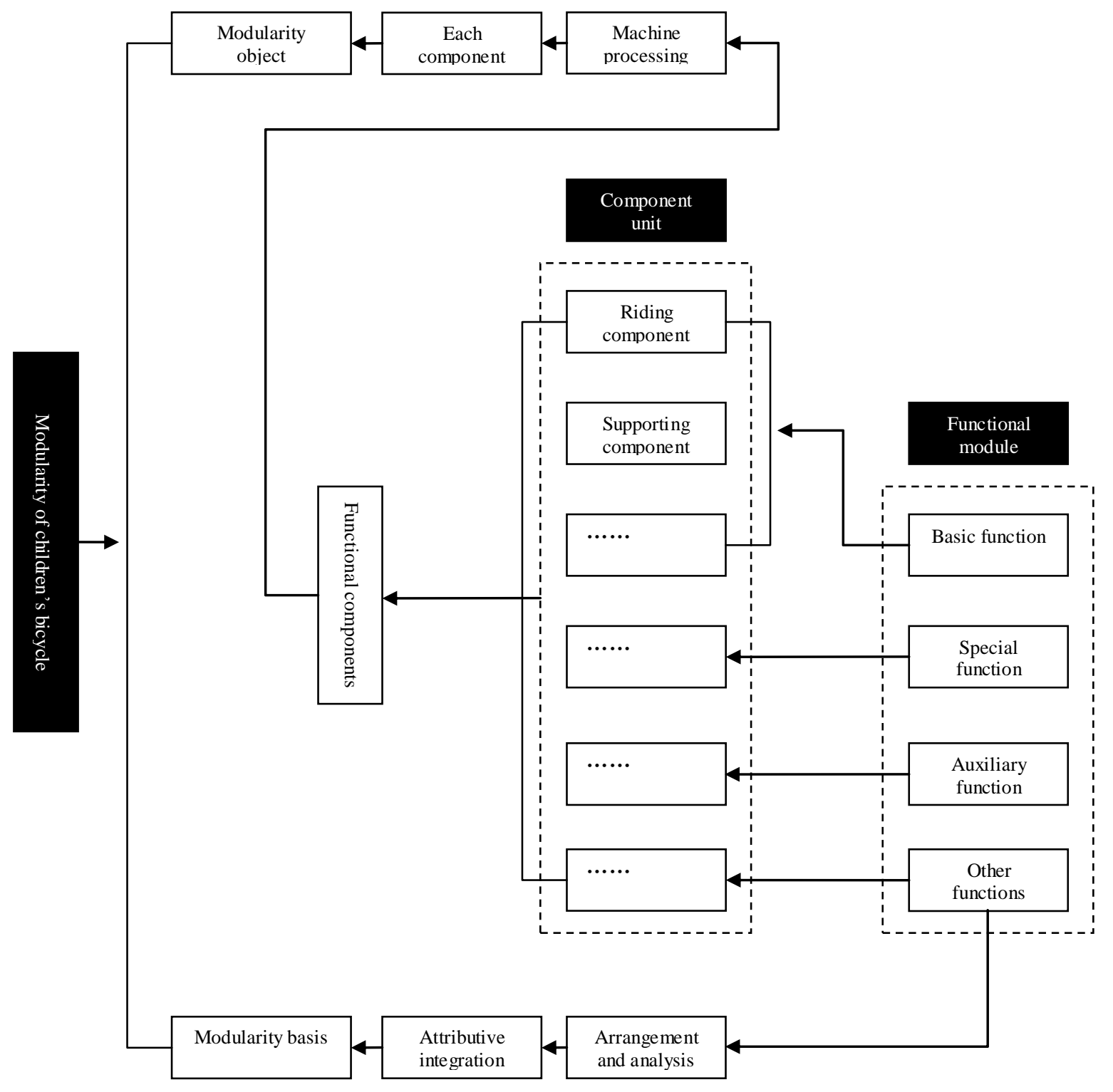

Fig. 1. Production steps of children's bicycle based on modularity

Production process after modularity is based on decomposition and arrangement of module. Decompose constituent parts of children's bicycle into several functional units according to decomposition method. Besides, different functional units can be further decomposed as more independent basic modules by degrees according to requirement of products of various series. These basic modules can be used as more universal or singular basic unit component with less functions. Application of modularity design can reduce design cycle and complexity, thus improving production efficiency greatly. For instance, new functions can be realized through small modification on frame structure and adding some basic unit modules, thus realizing previous changes which take great pains for a very small price and 
providing clients with finished product in a short period of time. What's more, high efficient design production will greatly perfect the image of enterprise in client's mind.

During the process of enterprise's development of products, design concept of modularity can be displayed in the following three situations: Conduct reformation design of modularity aimed at existed production line of enterprise, modularity design aimed at products on the whole production line and upgrade on modularity design aimed at products needing renewal of function. The above modularity design of children's bicycle starts with enterprise's entire production line of children's bicycle. In conclusion, sum up and sort out the three situations above, and find out common points among products of various series in all conditions, then start from here and systematically look for excellent modularity design scheme to optimize design and production plan to a large extent. Based on requirements of security and multi-function for children's bicycle, functional decomposition method can be mainly used to carry out modularity design.
In conclusion, this paper will discuss application mode of functional decomposition in production design of children's bicycle and feasibility analysis on it.

\section{B. Model Framework of Functional Decomposition}

Children's bicycle mainly falls into two categories: tricycle and two wheeled bicycle. Tricycle is fit for children at the age of 3 to 6 to have entertainment or to experience the transportation tool of bicycle while two wheeled bicycle is fit for children at the age of 6 to 14 to learn bicycle riding techniques of adults. It is easy to see that these two kinds of bicycles both have strong functionality, therefore their modularity design process emphasizes more on functional decomposition. Here, we will take two wheeled bicycle as the object for research. Parents' requirement for functions of children's bicycle is an important reference index for functional decomposition approach in design process. Realization of modularity design of products with different usages, division of modules and combination and assembly is exactly conducted under this premise. Visual display writer of functional decomposition draws the following model figure "Fig. 2":

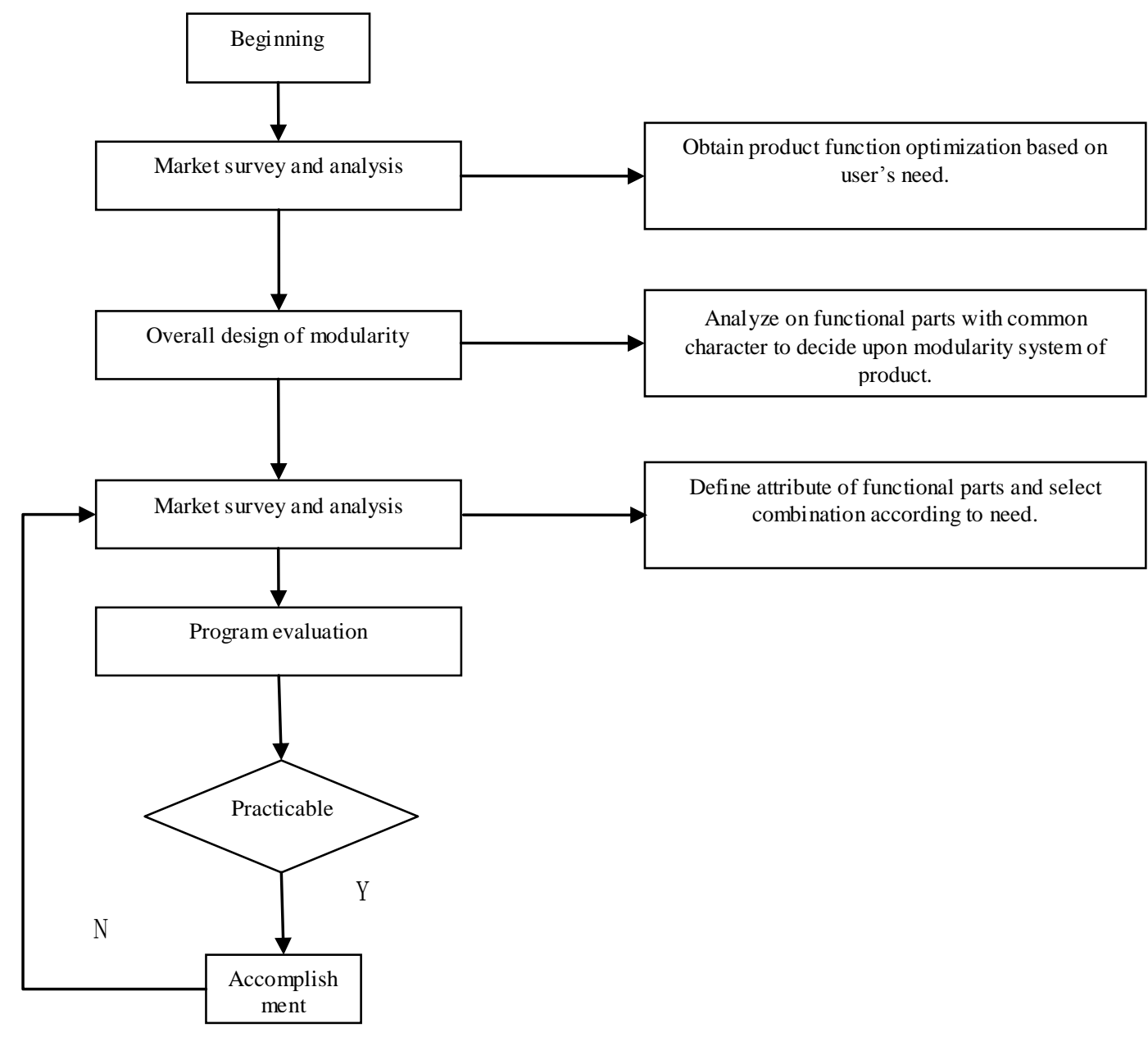

Fig. 2. Design model 
After analyzing on product design of many successful enterprises, we can find that, with no exception, successful products take user's need as design concept, seriously analyze on user's need and put it into products. Design starting with humanization is also an influential aspect for realization of modularity optimization design of children's bicycle. Enterprise should sum up and sort out client's need in various aspects for children's bicycle collected from market survey, facilitating specific division of different modules of bicycle. Main features and functions of children's two wheeled bicycle are important indicator and basis for guiding each link of modularity design. During the process of modularity design, we should make classification rules and decompose products as several functional modules with excellent combination degree. When conducting delivery inspection, we should carefully evaluate whether samples meet the anticipation.

\section{Feasibility Analysis}

Due to small dimension of children's bicycle and gradual phasing out with children growing up, abundant market survey should be done before design of bicycle. We should conduct analysis on each part of bicycle and start overall design with consideration for its features according to functional decomposition approach after clarifying client need. Analysis on each module is displayed in "Table I".

TABLE I. MODULE ANALYSIS OF MODULARITY CHILDREN'S BICYCLE

\begin{tabular}{|c|c|c|c|}
\hline \multirow{7}{*}{$\begin{array}{l}\text { Modularity } \\
\text { product } \\
\text { system }\end{array}$} & \multirow[t]{3}{*}{ Basic module } & \multirow[t]{3}{*}{$\begin{array}{l}\text { Basic } \\
\text { function }\end{array}$} & $\begin{array}{l}\text { Framework of bicycle } \\
\text { body }\end{array}$ \\
\hline & & & $\begin{array}{l}\text { Foot protection and } \\
\text { guardrail }\end{array}$ \\
\hline & & & Wheel guard \\
\hline & $\begin{array}{l}\text { Auxiliary } \\
\text { module }\end{array}$ & $\begin{array}{l}\text { Auxiliary } \\
\text { function }\end{array}$ & Joint of each part \\
\hline & \multirow{2}{*}{$\begin{array}{l}\text { Adaptive } \\
\text { module }\end{array}$} & \multirow{2}{*}{$\begin{array}{l}\text { Adaptive } \\
\text { function }\end{array}$} & Cushion \\
\hline & & & Rotating parts \\
\hline & Special module & $\begin{array}{l}\text { Special } \\
\text { function }\end{array}$ & Braced frame \\
\hline \multirow{4}{*}{$\begin{array}{l}\text { Mixed } \\
\text { product } \\
\text { design }\end{array}$} & \multirow{4}{*}{ Non-module } & \multirow{4}{*}{$\begin{array}{l}\text { User } \\
\text { dedicated } \\
\text { function }\end{array}$} & Sunshade \\
\hline & & & Dinner plate \\
\hline & & & Toys on the bicycle \\
\hline & & & Color and so on \\
\hline
\end{tabular}

Combining with establishment of modularity system in the above table, we can divide children's bicycle series products into several effective functional or structural module and produce freely changeable and continuously usable modularity functional part. Users can change structure and function of products by themselves and regroup for continuous use according to need in different times and different specific environments. Or users can purchase corresponding functional part of relevant functional module from manufacturer to expand functions of product. For instance, users can use some draw keys and connecting keys to connect braced frame of baby stroller effectively, changing it into basic frame of baby walker, dining car and so on which can be used later. Then, choose different adaptive and auxiliary modules for change and assembly, achieving some adaptive functions and auxiliary functions.

\section{APPLICATION OF MODULARITY DESIGN APPROACH OF CHILDREN'S BICYCLE}

In this chapter, we will apply and verify modularity design approach and feasibility analysis of children's bicycle described previously to a certain extent.

\section{A. Object of Modularity Design}

Compared with other children's vehicles, like trolley, walker, scooter and so on, children's bicycle is most widely used and is the tool which can be used by almost every child. During the growing process of school age children, bicycle is also an indispensable enlightenment product. Taking children's bicycle as the object of modularity design is typical and universally meaningful. Due to difference in user age and gender and so on, children's bicycle also has various series.

\section{B. Implementation of Modularity Design}

Statistical analysis on home environment of various users and different consumption levels must be done before designing children's bicycle to define product location, product function, manufacturing cost and so on. Among them, we should especially pay attention to different families' requirements and suggestions for children's bicycle and conduct product module partition based on it.

Firstly, analyze on features of each functional part of children's bicycle according to functional decomposition approach "Table II":

TABLE II. FEATURES OF CHILDREN'S BICYCLE

\begin{tabular}{|l|l|l|}
\hline Functional part & $\begin{array}{l}\text { Common name } \\
\text { of each part }\end{array}$ & Basic features \\
\hline \multirow{2}{*}{ Riding function } & Saddle & $\begin{array}{l}\text { Soft and comfortable, suitable for } \\
\text { children }\end{array}$ \\
\cline { 2 - 3 } & Pedal & Make power \\
\hline $\begin{array}{l}\text { Support system } \\
\text { function }\end{array}$ & Frame & $\begin{array}{l}\text { Arc structure, triangle structure, } \\
\text { folding structure and so on }\end{array}$ \\
\hline Drive function & Chain & $\begin{array}{l}\text { Transmit power from pedal for } \\
\text { wheels }\end{array}$ \\
\hline Motor system & Wheel & Front wheel and rear wheel \\
\cline { 2 - 3 } & Brake & Front and rear brake \\
\hline \multirow{2}{*}{ Others } & Rearview mirror & Located on handlebar \\
\cline { 2 - 3 } & Front basket & $\begin{array}{l}\text { Contain some toys or small items } \\
\text { for children }\end{array}$ \\
\cline { 2 - 3 } & Rear basket & $\begin{array}{l}\text { The same as front basket, have } \\
\text { beautiful effect at the same time }\end{array}$ \\
\hline
\end{tabular}

According to the above table, we can define modularity system of children's bicycle. Based on rules of functional 
module component system, we remake the table which includes five modules as follows "Table III":

TABLE III. FEATURES OF MODULARITY CHILDREN'S BICYCLE

\begin{tabular}{|c|c|c|c|}
\hline \multirow{9}{*}{$\begin{array}{l}\text { Modularity } \\
\text { product } \\
\text { system }\end{array}$} & \multirow{4}{*}{$\begin{array}{l}\text { Basic } \\
\text { modules }\end{array}$} & \multirow{4}{*}{$\begin{array}{l}\text { Basic } \\
\text { functions }\end{array}$} & Wheel guard \\
\hline & & & Brake \\
\hline & & & Wheel \\
\hline & & & Chain \\
\hline & \multirow{2}{*}{$\begin{array}{l}\text { Auxiliary } \\
\text { module }\end{array}$} & \multirow{2}{*}{$\begin{array}{l}\text { Auxiliary } \\
\text { function }\end{array}$} & Front and rear basket \\
\hline & & & Auxiliary wheel \\
\hline & \multirow{2}{*}{$\begin{array}{l}\text { Adaptive } \\
\text { module }\end{array}$} & \multirow{2}{*}{$\begin{array}{l}\text { Adaptive } \\
\text { function }\end{array}$} & Saddle \\
\hline & & & Rotating parts \\
\hline & $\begin{array}{l}\text { Special } \\
\text { module }\end{array}$ & $\begin{array}{l}\text { Special } \\
\text { function }\end{array}$ & $\begin{array}{l}\text { Braced frame (large, } \\
\text { medium and small) }\end{array}$ \\
\hline \multirow{4}{*}{$\begin{array}{l}\text { Mixed } \\
\text { product } \\
\text { system }\end{array}$} & \multirow{4}{*}{ Non-module } & \multirow{4}{*}{$\begin{array}{l}\text { User } \\
\text { dedicated } \\
\text { function }\end{array}$} & Hue \\
\hline & & & Rearview mirror \\
\hline & & & Variator \\
\hline & & & $\cdots \cdots$ \\
\hline
\end{tabular}

The new table uses modularity design approach to systematize design and manufacturing of children's bicycle. Division of functional structure defines different modules. The factory or enterprise can choose corresponding modules to assemble finished bicycle according to specific requirements of user and retail dealer. Response speed of this approach is rapid and it greatly reduces product development process. So to speak, modularity design approach can modulate contradiction between large scale production of enterprise and various personalized customization of different clients.

New production method makes it available for users to choose and assemble freely according to their specific needs. For instance, client buys a bicycle for his child at the age of 6 to satisfy child's curiosity and teach the child how to ride a bicycle. Under this condition, the client just needs to choose corresponding functional modules from all modules and directly assembles; With the child growing up and with help of auxiliary wheel, the child has learned how to ride. At this time, the client can dismantle auxiliary wheel and change a large size frame. For the sake of safety, rearview mirror can also be added. Thus, we can not only increase service life of children's bicycle, but also effectively save the resources.

\section{CONCLUSION}

Introducing of modularity concept in children's bicycle design is helpful for improving of product performance and satisfying children's need. Component elements of modularity system are all relatively independent units, making it convenient for maintenance and replacement and having excellent maintainability. This paper takes children's bicycle which is an extremely typical product category as the object, researches and discusses on children's bicycle modularity design approach, summarizes modularity design approach which emphasizes on functional decomposition and combines with design practice to demonstrate examples.

\section{REFERENCES}

[1] Wu Xiaoli and Qiu Tingting. Innovative Design and Engineering Analysis of Children's Bicycle of Combined Type $[\mathrm{J}]$. Machine design and research, 2010(06): 124-128.

[2] Bao Fangyun. Sino-EU Standard Comparison--Safety Requirement for Children's Bicycle[J]. China Bicycle, 2012(12): 42-48.

[3] Wu Xiaoli, Wang Yuxing and Xue Chengqi. Children's Bicycle of Functional Combined Type Designed by FAST Method[J]. Machine Design and Research, 2012(01): 98-101.

[4] Wu Xiaoli and Xue Chengqi. Innovative Design of a Kind of Children's Entertainment Travel Tool of Combined Type[J]. Engineering Design Journal, 2012(03): 236-240.

[5] Wang Zhenwei. Discussion on Morphological Bionics of Children's Bicycle[J]. China Packaging Industry, 2013(20): 24-25.

[6] Chen Jian, Xu Xiaoguang and Bi Kaijun. Test Point Research of Children's Monowheel Tandem Bicycle[J]. Testing Technology Journal, 2013(04): 282-286.

[7] Jiang Yufeng. Comparison of and Analysis on Safety Requirement of Children's Bicycle and Bicycle[J]. China Bicycle, 2015(01): 100-103.

[8] Tong Shizhong. Design Method and Application of Modularity Principle[M]. China Standards Press, 2000.5.

[9] Jia Yanlin. Modularity Design[M]. Beijing: China Machine Press, 1993

[10] Jiang Hui. Computer-assisted Machine Tool Modularity Scheme Design Theory and Practice[D]. Tianjin: Tianjin University, 1998. 